\title{
Circadian secretion of cortisol and melatonin in cluster headache during active cluster periods and remission
}

\author{
ELISABET WALDENLIND,* SVEN A GUSTAFSSON, $†$ KARL EKBOM,* \\ LENNART WETTERBERG
}

\begin{abstract}
From the Department of Neurology, Söder Hospital, ${ }^{*}$ Stockholm, Department of Clinical Chemistry, Huddinge Hospital, $\uparrow$ Huddinge, and the Department of Psychiatry, St Göran's Hospital, $\ddagger$ Stockholm, Sweden
\end{abstract}

SUMMARY The cyclic nature of cluster headache warranted a study of the 24-hour rhythms of serum cortisol and melatonin. They were both altered during cluster periods as compared with periods of remission and healthy controls. The 24-hour mean and maximal cortisol levels were higher and the timing of the cortisol minimum was delayed as compared to the same patients in remission. Although there was no relation between the cortisol and melatonin levels and headaches, the rise of cortisol following many attacks might in part represent an adaptive response to pain. The nocturnal melatonin maximum was lower during cluster periods than in remission. This finding, and the dysautonomic signs during attacks, may reflect a change of the vegetative tone in a hyposympathetic direction.

The cyclic nature of cluster headache and dysautonomic signs during attacks may suggest a dysfunction in the central nervous system related to rhythm-regulating centres. Recently, increasing interest has been focused on changes in hormonal biological rhythms in cluster headache patients. ${ }^{1-9}$ The pineal hormone melatonin is influenced by bright light ${ }^{10}$ and is believed to reflect the circadian organisation of biological rhythms in several species including man. ${ }^{11}$ Serum cortisol also exhibits a circadian rhythm. A functional relation between the pineal gland and the hypothalamic-pituitary-adrenal axis has been suggested. 1213

We recently reported that the nocturnal levels of serum melatonin were lower in cluster headache during the active headache period than during the remission state. ${ }^{7}$ Decreased nocturnal serum melatonin levels in patients in an active cluster period as compared to normal healthy controls have also been reported. ${ }^{8}$ In the present paper the 24-hour rhythms of serum cortisol and melatonin were studied in cluster headache patients during active cluster periods

Address for reprint requests: Dr E Waldenlind, Dept of Neurology, Söder Hospital, S-100 64 Stockholm, Sweden.

Presented in part at the 2nd International Headache Congress, June 1985, Copenhagen.

Received 3 April 1986.

Accepted 23 May 1986 and remissions. Furthermore, the nocturnal urinary excretion of melatonin was examined in cluster headache and healthy control subjects.

\section{Patients and methods}

\section{Study of serum cortisol and melatonin}

Patients Thirty-one cluster headache patients were admitted to the hospital for the study during the years 1981 to 1984. They were diagnosed as suffering from episodic cluster headache $(n=27)$ according to Ekbom ${ }^{14}$ or as chronic cluster headache $(n=4)$ according to Ekbom and Olivarius. ${ }^{15}$ The age distribution and some anamnestic data are summarised in table 1 .

Serum cortisol was examined in all 31 patients. Eleven males and five females of the episodic cases were examined both during and between periods of cluster headache. Serum melatonin was studied in 20 episodic and four chronic cluster patients. From nine of the 20 patients with episodic cluster headache data were obtained both during a cluster period and during a remission. Some data from eight out of these nine patients have been reported previously. ${ }^{7}$

When examined during the remission period all patients were free of medication. During the active cluster period prophylactic therapy (methysergide, pizotifen, ergotamine tartrate) was stopped at least 3 days prior to the study. The patients were allowed to take paracetamol or acetylsalicylic acid as treatment for pain during attacks. No patient had had any steroid treatment during the previous year.

Control subjects Fourteen healthy individuals (eight females) served as controls (table 1). They were medical students or members of the hospital staff. They did not suffer from any headache or psychiatric disorder and did not take 
Table 1 Summary of clinical data in patients with cluster headache and healthy controls

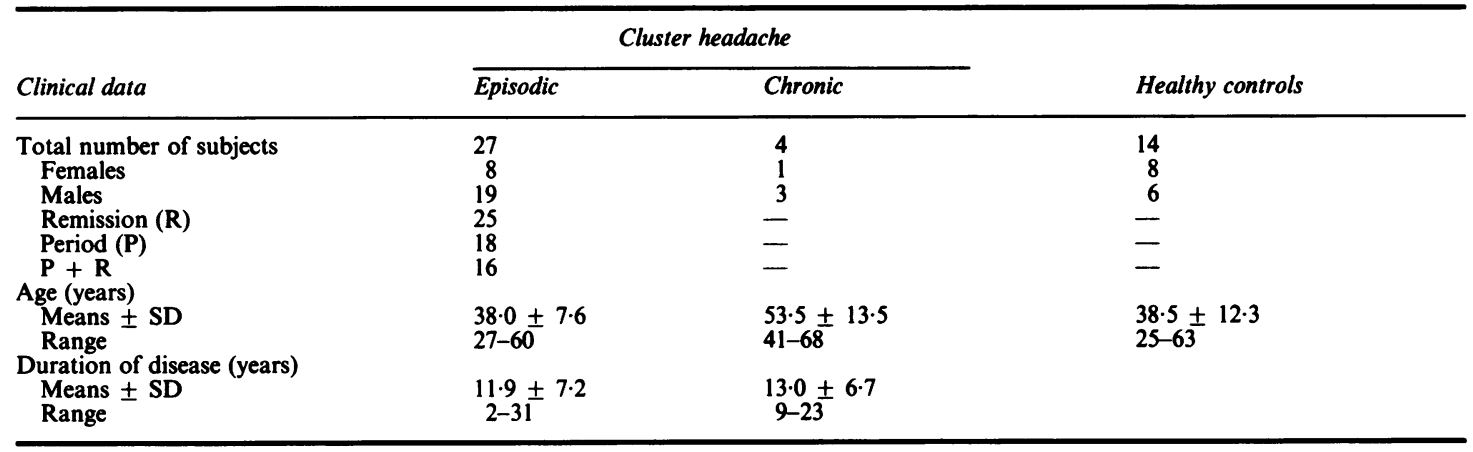

any medication.

Design of the study Patients and controls were admitted to the hospital in the early morning on the first day of the study. The females were examined on day 4 to 6 after onset of the last menstrual bleeding unless they were postmenopausal. None of the patients or the controls were taking oral contraceptives. An indwelling catheter was inserted into an antecubital vein between $12-13 \mathrm{~h}$, that is, at least one hour prior to the first blood sampling. It was kept patent by injection of $0.5 \mathrm{ml}$ of heparin $(50 \mathrm{IU} / \mathrm{ml})$ after each blood collection. The subjects were sleeping in a single room with the lights out from $22.30 \mathrm{~h}$. The blood samples at night were drawn in dim light. Blood samples were drawn every 4 hours during the day time and every other hour during the night, that is, at 14, 18, 22, 24, 02, 04, 06 and $10 \mathrm{~h}$. The first 12 patients (six in cluster period, six in remission) were studied every 4 hours from $14 \mathrm{~h}$ to $10 \mathrm{~h}$ the following day.

The patients made notes of the occurrence and duration of headache attacks. They gave a subjective grading of the headache intensity as mild (grade 1), moderate to severe (grade 2) and very severe (grade 3). They were also thoroughly interviewed about their headache notes, events during the study, and their sleep.

\section{Study of urine melatonin}

Patients and control subjects Thirty-three cluster patients (17 males) (aged 38.5 \pm 9.5, range 26-63 years) collected urine between $22 \mathrm{~h}$ and $06 \mathrm{~h}$. They have been described previously. ${ }^{37}$ Twenty-seven of the patients were examined during clinical remission and six during an active cluster period. Thirty healthy individuals (18 females) from the hospital staff (40.4 $\pm 13 \cdot 1$ years, range 23-63 years) also participated, selected as described above.

Assay The blood samples (serum) were kept frozen at $-20^{\circ} \mathrm{C}$ until assayed. Cortisol was determined by RIA using reagents obtained from Farmos Diagnostica, Turku, Finland. Within and between-assay variation was 2.9 and $5.8 \%$ respectively. Melatonin was analysed by RIA according to Wetterberg et al. ${ }^{16}$ The lower limit of detection is $0.01 \mathrm{nmol} / \mathrm{l}$. The coefficient of variation of the method is $6.8 \% .^{17}$

Statistical evaluation Wilcoxon's paired rank sum test was used when comparing data from the same patients in active cluster periods and remission. The Mann-Whitney U-test was used when comparing cluster patients with healthy controls. P-values less than $\mathbf{0 . 0 5}$ were considered significant. Two-sided tests were used.

Ethical approval Informed written consent was obtained from all participating patients and control subjects. The investigation was approved by the Ethics Committee at the Karolinska Institute.

\section{Results}

\section{Cortisol}

In fig 1 the mean values of serum cortisol were higher during the active cluster period on all sampling occasions compared with corresponding mean values of healthy controls. In order to characterise the 24-hour variation of serum cortisol the maximal and minimal cortisol values, their timing respectively and the 24-hour mean were further analysed. The 24-hour mean was calculated from the 4-hour samples (the values at 14, 18, 22, 02, 06 and $10 \mathrm{~h}$ ). Females and males were evaluated as one group, since there were no significant sex differences with respect to the 24-hour mean of cortisol, the maximal and minimal values (data not shown).

The maximal cortisol levels and the 24-hour means were significantly higher during the active cluster period $(p<0.025$ and $p<0.02)$, but not during clinical remission, as compared with healthy controls (table 2). The maximal cortisol levels occurred at $06 \mathrm{~h}$ or $10 \mathrm{~h}$ in both patients and controls with the exception of two cluster cases with active symptoms. Their maxima at $14 \mathrm{~h}$ and $02 \mathrm{~h}$ coincided with cluster attacks.

In order to obtain a more accurate estimate of the minimal serum cortisol level and its timing, only data from the patients with blood sampling every other hour at night were used (table 2). The minimum levels of cortisol were then found to be non-significantly higher during the active cluster period $(p<0 \cdot 10)$ as well as during the remission than in healthy controls. 


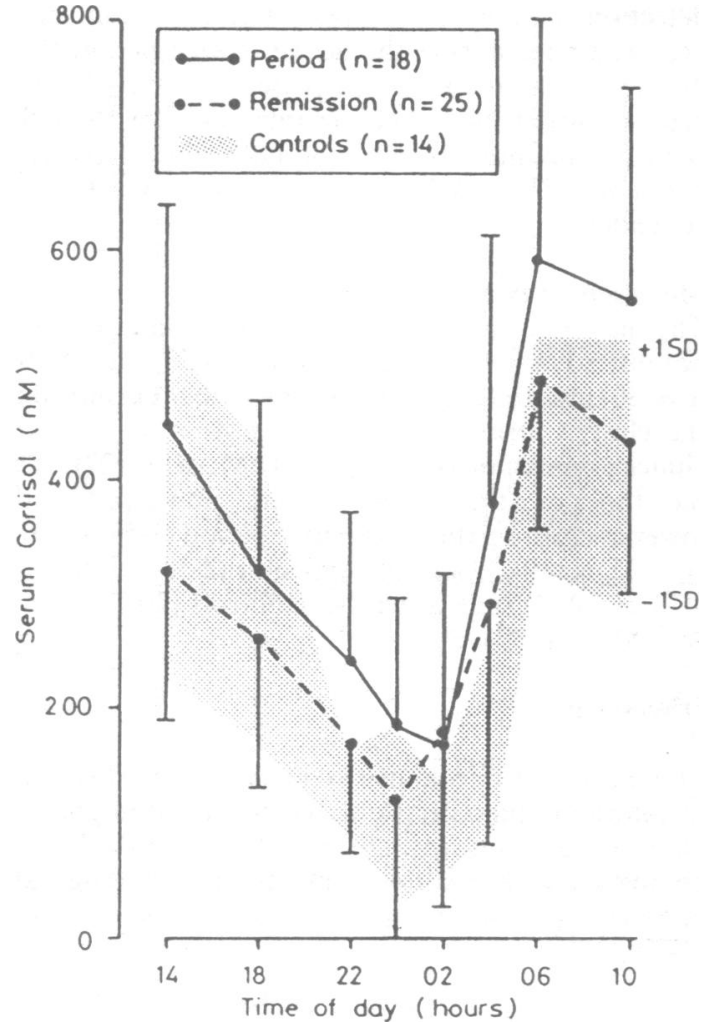

Fig 1 Circadian rhythm of serum cortisol in cluster headache patients in period and remission and healthy controls. Values given as means $\pm S D$.

The temporal distribution of the cortisol minimum (every other hour sampling during the night) is shown in fig 2. There was no difference in the timing of the cortisol minimum between healthy controls and clus- ter patients during or between active cluster periods.

Sixteen patients were studied both during an active cluster period and during remission (table 2). The 24-hour mean and maximal cortisol levels were significantly higher during the cluster period. $(p<$ 0.05 and $p<0.01$ respectively), but the minimal levels $(n=15)$ did not differ significantly between the active cluster period and remission $(p<0 \cdot 10)$. In the latter comparison one patient was excluded, who, owing to severe attacks showed no nadir. The cortisol minimum was delayed in most patients during the cluster period as compared to the remission ( $p<$ 0.05 , sign test). Thus the cortisol nadir appeared 2 hours later in $7 / 9$ patients (every other hour sampling) and 4 hours later in $2 / 6$ patients (every 4 hours sampling). In six cases the night minimum occurred at the same time during cluster period and remission.

\section{Headache attacks and cortisol}

A total of 28 cluster attacks occurred during the study in 12 out of 18 patients with active symptoms. The intensity of the headache attacks was graded as mild $(n=6)$, moderate to severe $(n=4)$ or very severe $(n$ $=18)$. Fifteen attacks $(54 \%)$ awakened the patients from sleep. Seven attacks (25\%) occurred between 04 and $06 \mathrm{~h}$ in the morning. Seventeen of the attacks coincided with the blood sampling or had ended within 30 minutes prior to the blood sampling.

Twenty-three attacks were followed by or coincided with a rise of serum cortisol (delta range 10-729, median 300). Fifteen attacks were followed by or coincided with either of the two highest levels of serum cortisol but 12 of these 15 attacks coincided with the early morning rise of serum cortisol. Samples taken during or after cluster attacks were significantly higher than at corresponding hours outside attacks $\left(p<0.05, \chi^{2}\right.$ test). In two cases a decrease of serum cortisol was found and in two the increase was slight

Table 2 Cortisol 24 hour mean, maximal and minimal levels and melatonin nocturnal maximal levels in serum from cluster headache patients and healthy controls. Means $\pm S D$. Wilcoxon's paired analysis (same individuals in period and remission). Mann-Whitney U-test (cluster patients vs healthy controls)

\begin{tabular}{|c|c|c|c|c|c|c|c|}
\hline \multirow[b]{2}{*}{ Subjects and clinical data } & \multirow{2}{*}{$\begin{array}{l}\text { Number } \\
\text { (n) }\end{array}$} & \multirow{2}{*}{$\begin{array}{l}\text { Cortisol } 24 \\
\text { hour mean* } \\
(n M)\end{array}$} & \multirow{2}{*}{$\begin{array}{l}\text { Cortisol } \\
\text { maximum } \\
(n M)\end{array}$} & \multicolumn{2}{|c|}{ Cortisol minimum $\|$} & \multicolumn{2}{|c|}{ Melatonin maximum } \\
\hline & & & & $\bar{n}$ & $(n M)$ & $\bar{n}$ & $(n M)$ \\
\hline $\begin{array}{l}\text { Healthy controls } \\
\text { Cluster headache (all) }\end{array}$ & 14 & $293 \pm 59$ & $512 \pm 115$ & 14 & $67 \pm 25$ & 11 & $0.27 \pm 0.17$ \\
\hline $\begin{array}{l}\text { Remission } \\
\text { Period } \\
\text { Chronic } \\
\text { Cluster headache (pairs) }\end{array}$ & $\begin{array}{r}25 \\
18 \\
4\end{array}$ & $\begin{array}{l}308 \pm 24 \\
378 \pm 88 t \\
342 \pm 84\end{array}$ & $\begin{array}{l}541 \pm 122 \\
671 \pm 203 \ddagger \\
534 \pm 183\end{array}$ & $\begin{array}{r}19 \\
12 \\
4\end{array}$ & $\begin{array}{r}74 \pm 34 \\
104 \pm 58 \\
99 \pm 29\end{array}$ & $\begin{array}{r}17 \\
11 \\
4\end{array}$ & $\begin{array}{l}0.25 \pm 0.14 \\
0.20 \pm 0.09 \\
0.26 \pm 0.09\end{array}$ \\
\hline $\begin{array}{l}\text { Remission } \\
\text { Period }\end{array}$ & $\begin{array}{l}16 \\
16\end{array}$ & $\begin{array}{l}281 \pm 80 \\
376 \pm 948\end{array}$ & $\begin{array}{l}521 \pm 127 \\
672 \pm 214 \dagger\end{array}$ & $\begin{array}{l}9 \\
9\end{array}$ & $\begin{array}{r}75 \pm 43 \\
100 \pm 53\end{array}$ & $\begin{array}{l}9 \\
9\end{array}$ & $\begin{array}{l}0.29 \pm 0.168 \\
0.21 \pm 0.09\end{array}$ \\
\hline
\end{tabular}

*Mean of values at 14, 18, 22, 02, 06, $10 \mathrm{~h}$.

tp $<0.01$.

$t \mathrm{p}<0.025$.

$\$ \mathrm{p}<0.05$.

$\|$ Subjects examined every other hour at night. 

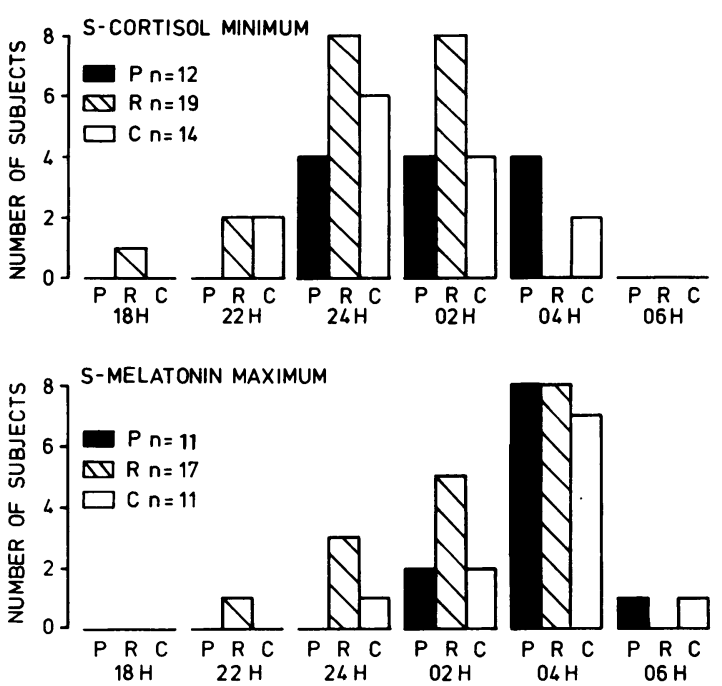

Fig 2 Distribution of the timing of the cortisol minimal and the melatonin maximal values in episodic cluster headache patients and healthy controls studied every other hour during the night. $P=$ cluster period, $R=$ remission, $C=$ healthy controls.

during the attack. Higher cortisol levels were also seen in patients with no attacks, although in a cluster period, than in the same patients in remission. In no case did a cluster attack coincide with the night minimum. However, there were seven incidences of headache during the interval following the night minimum sample.

\section{Cortisol in relation to melatonin}

As previously reported, ${ }^{7}$ significantly decreased maximal nocturnal serum melatonin levels were found during the active cluster period as compared with remission in nine patients studied twice $(p<0.05)$ (fig 3). The cortisol/melatonin ratio at $02 \mathrm{~h}$ was higher in $7 / 9$ patients in the active cluster period than in the remission (fig 3).

As compared with healthy controls $(n=11)$, nonsignificantly lower maximal nocturnal serum melatonin levels were found in cluster headache, both in the active period $(n=11)$ and in remission $(n=18)$ (table 2). Nor did the cortisol/melatonin ratios $\times 10^{-3}$ at $02 \mathrm{~h}$ differ between healthy controls $(0 \cdot 60$ \pm 0.34 , range $0.08-1.33$, median 0.52 ) and cluster patients in remission (mean 1.96, median 0.29 , range $0 \cdot 12-17 \cdot 1$ ) or active period (mean $2 \cdot 46$, median $0 \cdot 86$, range $0 \cdot 26-13 \cdot 6$ ).

All patients, except one, had a characteristic circadian rhythmicity with very low daytime melatonin levels and a nocturnal peak at $02 \mathrm{~h}$ or $04 \mathrm{~h}$ as in healthy controls (fig 2). In one patient examined during remission the melatonin levels were below the detection limit in all samples. The melatonin peak occurred later during the active cluster period than during the remission in $4 / 8$ patients. The melatonin peak occurred one sampling interval later than the cortisol minimum in $67 \%$ of both cluster patients and controls, and in the remaining subjects they coincided.

\section{Melatonin in nocturnal urine}

The melatonin concentration in nocturnal urine did not differ between healthy controls $(0.25 \pm 0 \cdot 15 \mathrm{nM}$; $\mathrm{n}=30$ ) and the cluster patients whether examined in the cluster period $(0.23 \pm 0.16 \mathrm{nM} ; \mathrm{n}=6)$ or in clinical remission $(0.31 \pm 0.24 n M ; n=27)$. The melatonin/creatinine ratios were non-significantly lower in cluster patients in active period $\left(1.59 \times 10^{-5}\right.$ $\left.\pm 0.71 \times 10^{-5}\right)$ and in remission $\left(2.50 \times 10^{-5} \pm\right.$ $\left.2 \cdot 13 \times 10^{-5}\right)$ than in healthy controls $\left(2.67 \times 10^{-5}\right.$ $\left.\pm 1.51 \times 10^{-5}\right)$.

\section{Discussion}

Previously the circadian rhythmicity of cortisol and melatonin in blood has only been studied in patients with active episodic or chronic cluster headache and compared with healthy controls. The findings are complex. In episodic cases serum cortisol ${ }^{689}$ and

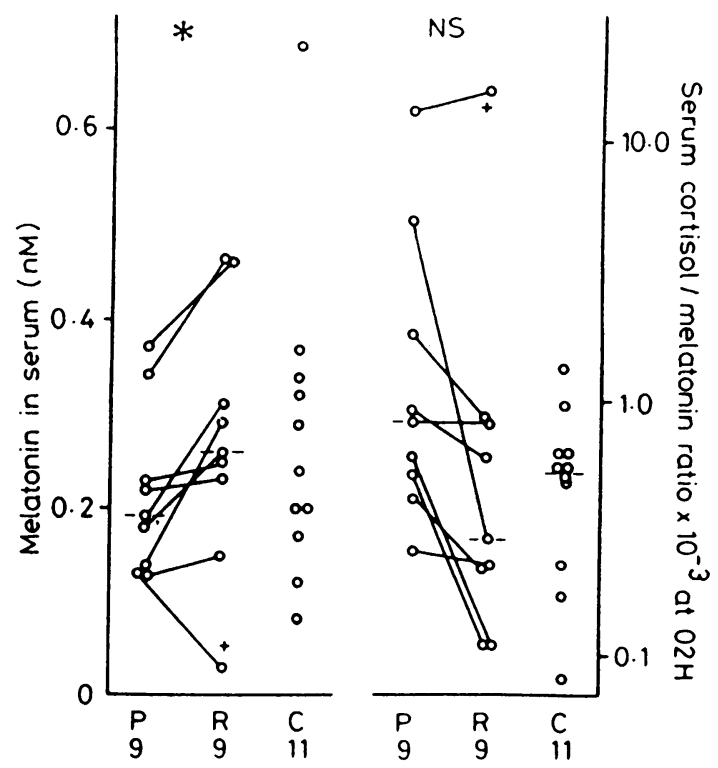

Fig 3 Scatter diagram of nocturnal maximal melatonin concentrations and cortisol/melatonin ratios $\times 10^{-3}$ at $02 \mathrm{~h}$ in 9 patients examined both during active periods $(P)$ and remission $(R)$ and in 11 healthy controls $(C)$. The median is shown for each group. ${ }^{*} p<0.05, N S p>0.05$ (Wilcoxon's paired test, 2-sided). 
melatonin ${ }^{8}$ have been found to exhibit a significant circadian periodicity but a phase delay of cortisol ${ }^{69}$ as well as a phase advance of cortisol and melatonin ${ }^{8}$ have been reported.

\section{Cluster periods}

In the present study the patients were studied both in the active cluster periods and during cluster-free intervals. Patients with active cluster headache had higher maximal and 24-hour mean cortisol levels and lower nocturnal melatonin levels than the same patients in remission. Furthermore a delay of the cortisol minimum was found in the active cluster as compared to the remission period. As compared with healthy individuals the secretion of cortisol was altered only in patients with active cluster symptoms. Thus our findings point to a temporary alteration in the secretion of cortisol and melatonin during the active cluster period.

It has not been possible to explain the regular appearance of cluster periods that often occur on a seasonal basis similar to that seen in manic-depressive disorders. In acutely depressed patients lower maximal nocturnal melatonin levels as well as higher cortisol minimal levels and a tendency to a phase advance have been found. ${ }^{121819}$ The melatonin levels in manic-depressive disorders remained altered after clinical recovery, while the cortisol rhythm was normalised. Thus low nocturnal melatonin levels seem to represent a permanent feature in some patients with manic-depressive disorders. In contrast, low melatonin levels in cluster headache were only found during the active cluster period which might provide some information as to the pathogenesis of cluster headache.

\section{Cluster attacks}

Hitherto there has been only one report on corticosteroid secretion in relation to cluster attacks. ${ }^{6}$ Seven patients in a cluster period were compared with healthy controls. In the two patients who had attacks the variations of serum cortisol were not found to exceed the spontaneous changes. In the present study, higher levels were seen during or after attacks, particularly when associated with the nocturnal rise of cortisol. Higher cortisol levels during the late night were also seen in patients with no attacks, although in an active period, than in the same patients in clinical remission.

Corticosteroid treatment is widely used, especially for episodic cluster headache. However, there is only limited evidence in the literature that steroids are effective since only a few, mainly open, studies have been made. ${ }^{20-22}$ Twenty-five per cent of the attacks in our patients occurred during the interval following the night minimum of cortisol. This might suggest a greater vulnerability to cluster attacks with low levels of serum cortisol and consequently a possible rationale for corticosteroid treatment of cluster headache.

The changes in serum cortisol levels may reflect a change in the basal rhythm of corticosteroid secretion during cluster periods related to the pathogenesis but a superimposed episodic stress-related secretion during pain is also likely. An activation of pituitary stress hormones in cluster headache has previously been reported in the form of elevated $\beta$-endorphin plasma levels during attacks ${ }^{23}$ and elevated plasma concentrations of $\beta$-lipotropin and $\beta$-endorphin during active cluster periods ${ }^{6}$ as compared with controls. In volunteers exposed to acute pain serum levels of $\beta$-endorphin, cortisol, prolactin, growth hormone and opioid activity have been studied, but only serum cortisol showed a significant increase as a function of noxious stimulation. ${ }^{24}$ Altered cortisol secretory patterns have been demonstrated in patients with somatic pain. ${ }^{2526}$ In a study of 30 patients complaining of somatic pain with different circadian rhythmicity, higher mean plasma levels of cortisol were found at the time of the highest pain intensity than in healthy pain-free controls. ${ }^{27}$ On the other hand, in a study of 25 migraine patients an inconsistent association between plasma cortisol levels and pain has been reported. ${ }^{28}$

Our patients are quite used to different tests and the test situation as such is not believed to be a major cause of stress. Several patients were examined twice. There was no difference in the cortisol 24-hour mean levels between the patients in clinical remission who were examined on the first $(n=12)$ or a second occasion $(n=13)$ (data not shown). In this context it is of interest that attacks of cluster headache often are associated with relaxation, for example, after a meal or rest, ${ }^{29}$ and seldom occur during physical or mental exercise. Igarashi et $\mathrm{l}^{30}$ have also shown that headaches after nitroglycerin provocation began concomitantly with a fall of plasma norepinephrine. These findings may point to a relation between the precipitation of cluster attacks and biochemical or vascular events following relaxation rather than stress. The anticipation of painful attacks during the active cluster headache period cannot, however, be ruled out as a cause of stress-induced cortisol secretion.

In our patients there was no obvious relation between the melatonin levels and the occurrence or timing of cluster attacks. There has hitherto been no evidence of a change of circulating melatonin in man in response to insulin tolerance testing, exercise or pneumoencephalography despite rises in other stressresponsive hormones. ${ }^{3132}$

The circadian melatonin rhythm is characterised by low daytime levels and a marked peak around $02 \mathrm{~h}$. The nocturnal peak has been shown to be abolished 
by $\beta$-adrenergic blocking agents, indicating a sympathetic regulation of the melatonin secretion. ${ }^{34}$ Cluster headache attacks are associated with symptoms of autonomic dysfunction, indicating either an increased parasympathetic tone or a decreased sympathetic tone or both. ${ }^{2935}$ Furthermore, treatment with $\beta$-adrenergic blocking agents, such as propranolol, does not improve cluster headache ${ }^{36}$ and may even aggravate this condition (Ekbom, Waldenlind, unpublished observation). Thus low nocturnal melatonin levels may be due to an altered $\beta$-adrenergic receptor function at the level of the pineal gland. Another tentative explanation of low serum melatonin may be an altered metabolism, for example lower concentrations of 5-HT available for the synthesis. The 5-HT concentration and the MAO $B$ activity might be lower in the pinealocyte in a similar way as previously shown in platelets. ${ }^{3738}$ An increased renal excretion of melatonin is probably not a major cause of low melatonin levels, since nocturnal urinary melatonin/creatinine ratios did not differ between our patients and healthy controls and the urinary volumes voided by the patients tended to be smaller.

In healthy subjects the rise of serum melatonin occurs concomitantly with the fall of the serum cortisol levels. A direct relationship between melatonin and cortisol or ACTH secretion has been postulated. ${ }^{1213}$ Also, there is evidence that the secretion of both melatonin and ACTH-cortisol are under noradrenergic control as well as dependent on serotoninergic activity. ${ }^{39}$ The available data seem to suggest that $\alpha$-receptors have a stimulating effect and $\beta$-receptors an inhibitory effect on central ACTH regulation. Taken together, it is possible that a change of the vegetative tone might explain the decrease of nocturnal serum melatonin levels and perhaps also the increase of serum cortisol during the active cluster period. In this context some important questions should be considered, as proposed by Lundberg, ${ }^{40}$ for example whether changes in endocrine balance can provoke a headache attack and whether the endocrine changes in cluster headache are specific.

In conclusion, we found a decrease of nocturnal serum melatonin and an increase of serum cortisol during the cluster periods. The phase delay of cortisol may reflect an impaired chrono-organisation of hormone secretion in cluster headache. Although there was no significant relation between melatonin levels and the occurrence of cluster headache attacks, high cortisol levels during cluster periods might in part represent an adaptive response to pain.

The skilful technical assistance by Ulrika Olsson, Ylva Friberg, Margareta Säker and the assistant nurses at the Neurological Department is gratefully acknowledged. The study was supported by grants from the Swedish Medical Society and the Karolinska Institute.

\section{References}

1 Polleri A, Masturzo P, Murialdo G, et al. Chronobiology of prolactin secretion: a marker in physiology and pathology. In: MacLeod RM, Scapagnini U, eds. Central and Peripheral Regulation of Prolactin Function. New York: Raven Press, 1980:207-20.

2 Ferrari E, Nappi G, Vailati A, Martignoni E, Bossolo PA, Polleri A. Circadian periodicity of plasma prolactin in some neurological diseases. Int J Chronobiol 1979;6:231-42.

3 Ferrari E, Canepari C, Bossolo PA, et al. Changes of biological rhythms in primary headache syndromes. Cephalalgia 1983;3(Suppl 1):58-68.

4 Polleri A, Nappi G, Murialdo G, Bono G, Martignoni E, Savoldi F. Changes in the 24-hour prolactin pattern in cluster headache. Cephalalgia 1982;2:1-7.

5 Nappi G, Micieli G, Sandrini G, Martignoni E, Lottici P, Bono G. Headache temporal patterns: towards a chronobiological model. Cephalalgia 1983;3(Suppl 1): 21-30.

6 Nappi G, Facchinetti F, Bono G, et al. Lack of $\beta$-endorphin and $\beta$-lipotropin circadian rhythmicity in episodic cluster headache: a model for chronopathology. In: Pfaffenrath V, Lundberg PO, Sjaastad $\mathrm{O}$, eds. Updating in Headache. Heidelberg: Springer Verlag, 1985:269-75.

7 Waldenlind E, Ekbom K, Friberg Y, Sääf J, Wetterberg L. Decreased nocturnal serum melatonin levels during active cluster headache periods. Opuscula Medica 1984;4:109-12.

8 Chazot G, Claustrat B, Brun J, Jordan D, Sassolas G, Schott B. A chronobiological study of melatonin, cortisol, growth hormone and prolactin secretion in cluster headache. Cephalalgia 1984;4:213-20.

9 Micieli G, Facchinetti F, Martignoni E, Bono G, Genazzani AR, Nappi G. Lowered and phase-delayed 24-h levels of circulating testosterone in cluster headache. Cephalalgia 1985;5(Suppl 3):364-5.

10 Lewy AJ, Wehr TA, Goodwin FK. Light suppresses melatonin secretion in humans. Science 1980;210: 1267-9.

11 Axelrod J. The pineal gland: a neurochemical transducer. Science 1974;184:1341-8.

12 Wetterberg L, Beck-Friis J, Kjellman BF, Ljunggren JG. Circadian rhythms in melatonin and cortisol secretion in depression. In: Usdin E, et al, eds. Frontiers of Biochemical and Pharmacological Research in Depression. New York: Raven Press, 1984:197-205.

13 Brismar $\mathrm{K}$, Werner $\mathrm{S}$, Thorén $\mathrm{M}$, Wetterberg $\mathrm{L}$. Metyrapone: an agent for melatonin as well as ACTH and cortisol secretion. J Endocrinol Invest 1985; 91:91-5.

14 Ekbom K. A clinical comparison of cluster headache and migraine. Acta Neurol Scand 1970;46(Suppl 41):1-48.

15 Ekbom K, Olivarius B de Fine. Chronic migrainous neuralgia-diagnostic and therapeutic aspects. Headache 1971;11:97-101. 
16 Wetterberg L, Eriksson O, Friberg Y, Vangbo B. A simplified radioimmunoassay for melatonin and its application to biological fluids. Preliminary observations on the half-life of plasma melatonin in man. Clin Chim Acta 1978;86:169-77.

17 Beck-Friis J, von Rosen D, Kjellman BF, Ljunggren JG, Wetterberg L. Melatonin in relation to body measures, sex, age, season and the use of drugs in patients with major affective disorders and healthy subjects. Psychoneuroendocrinology 1984;9:261-77.

18 Beck-Friis J, Ljunggren J-G, Thorén M, von Rosen D, Kjellman BF, Wetterberg L. Melatonin, cortisol and ACTH in patients with major depressive disorder and healthy humans with special reference to the outcome of the dexamethasone suppression test. Psychoneuroendocrinology 1985;10:173-86.

19 Branchey L, Weinberg U, Branchey M, Linkowski P, Mendlewicz J. Simultaneous study of 24-hour patterns of melatonin and cortisol secretion in depressed patients. Neuropsychobiology 1982;8:225-32.

20 Jammes JL. The treatment of cluster headaches with prednisone. Dis Nerv Syst 1975;36:375-6.

21 Couch JR Jr, Ziegler DK. Prednisone therapy for cluster headache. Headache 1978;18:219-21.

22 Kudrow L. Comparative results of prednisone, methysergide and lithium therapy in cluster headache. In: Greene R, ed. Current Concepts of Migraine Research. New York: Raven Press, 1978:159-63.

23 Appenzeller O, Atkinson RA, Standefer JC. Serum $\beta$-endorphin in cluster headache and common migraine. In: Rose FC, Zilkha KJ, eds. Progress in Migraine Research. Bath: Pitman, 1981:106-9.

24 Bullinger M, Naber D, Pickar D, et al. Endocrine effects of the cold pressor test: relationships to subjective pain appraisal and coping. Psychiatry Res 1984;12:227-33.

25 Shenkin HA. The effect of pain on the diurnal pattern of plasma corticoid levels. Neurology 1964;14:1112-7.

26 Lascelles PT, Evans PR, Merskey H, Sabur MA. Plasma cortisol in psychiatric and neurological patients with pain. Brain 1974;97:533-8.

27 Domzal T, Szczudlik A, Kwasucki J, Zaleska B, Lypka A. Plasma cortisol concentrations in patients with different circadian pain rhythm. Pain 1983;17:67-70.

28 Ziegler DK, Hassanein RS, Kodanaz A, Meek JC.
Circadian rhythms of plasma cortisol in migraine. J Neurol Neurosurg Psychiatry 1979;42:741-8.

29 Ekbom K. Patterns of cluster headache with a note on the relations to angina pectoris and peptic ulcer. Acta Neurol Scand 1970;46:225-37.

30 Igarashi H, Sakai F, Tazaki Y, Kanda T. The role of the sympathetic nervous system in the pathogenesis of cluster headache. Cephalalgia 1985;5(Suppl 3):362-3.

31 Vaughan GM, McDonald SD, Jordan RM, et al. Melatonin concentration in human blood and cerebrospinal fluid: relationship to stress. J Clin Endocrinol Metab 1978;47:220-3.

32 Wetterberg L. Melatonin in humans. Physiological and clinical studies. J Neural Transm 1978;(Suppl 13): 289-310.

33 Vaughan GM, McDonald SD, Jordan RM, Allen JP, Bell R, Stevens EA. Melatonin, pituitary function and stress in humans. Psychoneuroendocrinology 1979;4: 351-62.

34 Hanssen T, Heyden T, Sundberg I, Wetterberg L. Effect of propranolol on serum-melatonin. Lancet 1977;ii: 309.

35 Ekbom K, Lindahl J. Effect of induced rise of blood pressure on pain in cluster headache. Acta Neurol Scand 1970;46:585-600.

36 Strahlman ER. Cluster headache. Johns Hopkins Med J 1982;150:246-50.

37 Waldenlind E, Sääf J, Ekbom K, Ross S, Wahlund L-O, Wetterberg L. Kinetics and thermolability of platelet monoamine oxidase in cluster headache and migraine. Cephalalgia 1984;4:125-34.

38 Waldenlind E, Ross SB, Sääf J, Ekbom K, Wetterberg L. Concentration and uptake of 5-hydroxytryptamine in platelets from cluster headache and migraine patients. Cephalalgia 1985;5:45-54.

39 Delitalia G. Neurotransmitter control of anterior pituitary hormone secretion and its clinical implications in man. In: Besser GM, Martini L, eds. Clinical Neuroendocrinology. Vol II. New York: Academic Press, 1982:67-138.

40 Lundberg PO. Endocrine headaches. In: Vinken PJ, Bruyn GW, Klawans HL, Clifford Rose F, eds. Handbook of Clinical Neurology. Amsterdam: Elsevier Science Publishers 1986;48:431-40. 